\title{
Strength of Si Wafers with \\ Microcracks: A Theoretical Model
}

Conference Paper NREL/CP-520-42556

May 2008

\section{Preprint}

P. Rupnowski and B. Sopori

National Renewable Energy Laboratory

Presented at the 33rd IEEE Photovoltaic Specialists Conference San Diego, California

May 11-16, 2008
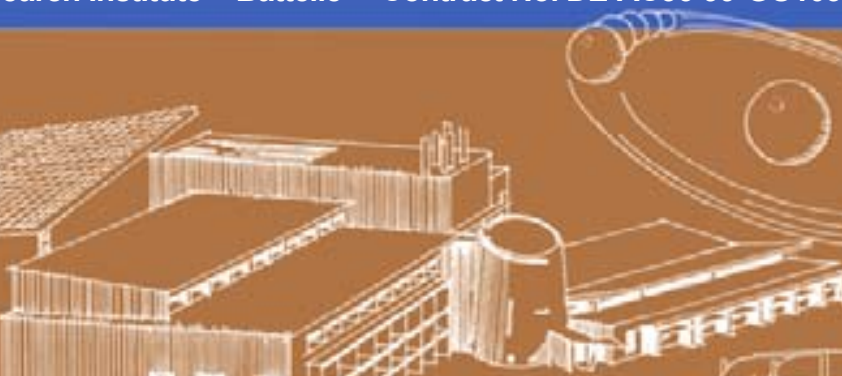


\section{NOTICE}

The submitted manuscript has been offered by an employee of the Midwest Research Institute (MRI), a contractor of the US Government under Contract No. DE-AC36-99G010337. Accordingly, the US Government and MRI retain a nonexclusive royalty-free license to publish or reproduce the published form of this contribution, or allow others to do so, for US Government purposes.

This report was prepared as an account of work sponsored by an agency of the United States government. Neither the United States government nor any agency thereof, nor any of their employees, makes any warranty, express or implied, or assumes any legal liability or responsibility for the accuracy, completeness, or usefulness of any information, apparatus, product, or process disclosed, or represents that its use would not infringe privately owned rights. Reference herein to any specific commercial product, process, or service by trade name, trademark, manufacturer, or otherwise does not necessarily constitute or imply its endorsement, recommendation, or favoring by the United States government or any agency thereof. The views and opinions of authors expressed herein do not necessarily state or reflect those of the United States government or any agency thereof.

Available electronically at http://www.osti.gov/bridge

Available for a processing fee to U.S. Department of Energy and its contractors, in paper, from:

U.S. Department of Energy

Office of Scientific and Technical Information

P.O. Box 62

Oak Ridge, TN 37831-0062

phone: 865.576 .8401

fax: 865.576 .5728

email: mailto:reports@adonis.osti.gov

Available for sale to the public, in paper, from:

U.S. Department of Commerce

National Technical Information Service

5285 Port Royal Road

Springfield, VA 22161

phone: 800.553 .6847

fax: 703.605.6900

email: orders@ntis.fedworld.gov

online ordering: http://www.ntis.gov/ordering.htm 


\title{
STRENGTH OF SI WAFERS WITH MICROCRACKS: A THEORETICAL MODEL
}

\author{
Przemyslaw Rupnowski and Bhushan Sopori \\ National Renewable Energy Laboratory, Golden, CO 80401, USA
}

\begin{abstract}
Wafer breakage is a major problem in the photovoltaic industry and becomes more serious as the industry attempts to use thinner wafers. It is well established that the poor strength of PV wafers is primarily due to the presence of residual microcracks, which are generated by cutting and wafering procedures and are not removed by subsequent etching of the wafers. This paper addresses fracture mechanics modeling of the strength of silicon PV wafers. We are showing that the surface damage, which includes the subsurface microcracks, determines the ultimate strength of the PV wafers. The modeling of PV wafers consists of Monte Carlo simulations and finiteelement analysis that is supported by the fracture energy theory for curved cracks. As an example, a virtual experiment on a statistical set of 100 wafers subjected to uniaxial tension is performed. The predicted strength distribution is shown to match well with the experimental results available in the literature.
\end{abstract}

\section{INTRODUCTION}

In a typical manufacturing facility, production yield losses resulting from cracking can be as high as $5 \%-10 \%$. The problem of fracture strength becomes even more important when the new thinner and large-area wafers are produced. To successfully reduce silicon usage and maintain high production yield, one needs to understand the fracture behavior of silicon wafers. This paper concentrates on the modeling of the strength of photovoltaic (PV) wafers. First, a general description based on a multimodal Weibull distribution will be presented for the strength of a silicon specimen with bulk, surface, and edge imperfections. Next, a specific case is analyzed of a PV wafer with surface damage that takes the form of subsurface microcracks.

\section{STRENGTH OF BRITTLE MATERIAL}

The classical approach (e.g., Ref. [1]) relates the strength of a brittle specimen to its volume. According to this approach, the probability $F_{V}(\sigma)$ that the specimen survives load $\sigma$ is given by:

$$
F_{V}(\sigma)=\exp \left(-\int_{V}\left(\frac{\sigma-\gamma_{V}}{\alpha_{V}}\right)^{\omega_{V}} d V\right)
$$

where $\gamma_{V}, \alpha_{V}$, and $\omega_{V}$ are the three parameters of the Weibull distribution. In the case of the multiaxial stress state, we need to regard $\sigma$ as a position-dependent effective stress [2].

To accurately describe the distribution of strength within a given set of wafers with more than one failure mode, a multi-modal (mixed) Weibull [3,4] distribution should be employed. For a typical brittle material like silicon, the following three failure modes can be distinguished: bulk, surface, and edge mode (see Fig. 1). By surface failure mode, one should understand a mode in which a failure initiates at a surface or subsurface defect and causes fracture of a specimen. Similarly, the edge mode and bulk mode represent cases when the failure is caused by imperfections in the bulk and at the edge of a wafer, respectively.

Let's now assume that the probability of survival for a wafer in which only the surface damage is present is

$$
F_{A}(\sigma)=\exp \left(-\int_{A}\left(\frac{\sigma-\gamma_{A}}{\alpha_{A}}\right)^{\omega_{A}} d A\right)
$$

Likewise, let's define the survival probability of a wafer without any defects on the surface or in the bulk (only the edge damage is present) as

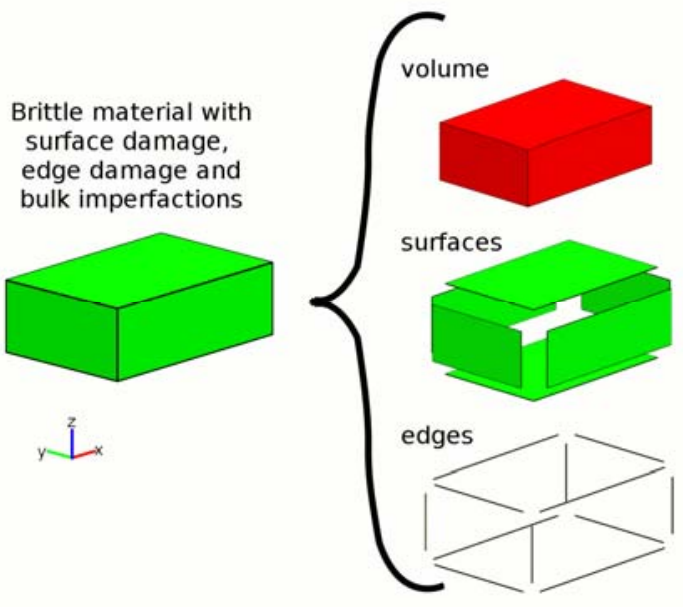

Fig. 1. Volume, surface, and edge zones for a general silicon specimen 


$$
F_{L}(\sigma)=\exp \left(-\int_{L}\left(\frac{\sigma-\gamma_{L}}{\alpha_{L}}\right)^{\omega_{L}} d L\right)
$$

In the above two expressions, $A$ represents the surface area, $L$ stands for the edge length, and $\gamma_{A}, \gamma_{L}, \alpha_{A}, \alpha_{L}, \omega_{A}$, $\omega_{L}$ are Weibull parameters, which are different from the parameters in expression (1). The other significant difference is that in expressions (2) and (3) the integration is performed over the surface area and edge length, instead of over the sample volume.

Formulas (1)-(3) describe the three failure modes of a silicon specimen that represent the volume (bulk), area, and edge components. Based on the weakest-link property, they can be combined to yield the effective probability of survival for the entire wafer:

$$
F(\sigma)=F_{V}(\sigma) \cdot F_{A}(\sigma) \cdot F_{L}(\sigma) .
$$

Combining all the above expressions gives:

$$
\begin{aligned}
& F(\sigma)=\exp \left[-\int_{V}\left(\frac{\sigma-\gamma_{V}}{\alpha_{V}}\right)^{\omega_{V}} d V\right. \\
& \left.\quad-\int_{A}\left(\frac{\sigma-\gamma_{A}}{\alpha_{A}}\right)^{\omega_{A}} d A-\int_{L}\left(\frac{\sigma-\gamma_{L}}{\alpha_{L}}\right)^{\omega_{L}} d L\right]
\end{aligned}
$$

\section{STRENGTH OF CAST UNPOLISHED PV WAFER}

A majority of silicon substrates for PV applications are manufactured by casting of a multicrystalline silicon (mcSi) ingot followed by wafer sawing using multi-wire sawing systems. As was described in detail in Ref. [5], the material removal during sawing can be regarded as a series of micro-indentations that lead to subsurface microcracking. Thus, the surface of a post-sawn wafer is not only rough, but it contains deep subsurface damage, as well $[6,7]$. The maximum depth of microcracks depends on many parameters such as slurry particle size, and sawing load and speed, and was reported in the range of $10-70 \mu \mathrm{m}$. It should also be noted that in a typical manufacturing process, the $10 \mu \mathrm{m}$ of the postsawn surface damage is etched off [8]. As a result of etching, the depth of subsurface microcracks is reduced and some crack tips can also be blunted. Both of these effects reduce fracture initiation potential of the subsurface microcracks. Nevertheless, etching does not always remove the entire layer with the sawing damage and the deep subsurface cracks remain in the wafer, reducing its effective strength.

In the case of a typical cast unpolished mc-Si wafer some additional valid assumptions can be introduced to the strength general Equation (5). First, it is reasonable to assume that due to the large surface area and relatively small volume, the strength of such wafers is determined mainly by the subsurface and/or near-edge damage. In other words, the volume failure mode can be neglected. The second assumption is related to the effect of edge defects. The edge damage has not yet been well quantified, and the appropriate characterization data are not available in the literature. What we know is that in the typical industry process, the silicon blocks are polished before slicing to achieve almost mirror-like smoothness of the block faces. Block polishing leads to the reduction of wafer-edge damage and the increase of the ultimate strength of the wafers. Consequently, in such wafers, the edge failure mode can be also neglected. What we are left with is the surface component expressed by expression (2).

\section{MONTE CARLO AND FRACTURE MECHANICS SIMULATIONS}

The main objective of Monte Carlo (MC) simulations developed in this study is to predict the strength distribution of silicon PV wafers. The presented technique is very general and allows for modeling of wafers of various sizes and shapes that are subjected to any type of loading. As an example, simulation results for a 5" x 5" wafer subjected to uniaxial tension will be presented. Bulk, surface, and edge defects can be modeled theoretically using the proposed MC technique; however, this study focuses on the surface damage.

To perform MC simulations, we go by the following procedure. First, we generate a set of 100 virtual wafers. Each wafer contains 100 surface cracks (50 on each side), which are randomly distributed and oriented. Fig. 2 depicts an example of one 5" $\times 5$ " wafer with surface microcracks used in the MC simulation. For the sake of legibility, the cracks are magnified 20 times in the figure. The maximum load for each wafer is calculated subsequently using the fracture-mechanics method combined with the weakest-link principle. The next step includes statistical analyses of the results for all 100 wafers to obtain the strength distribution. Finally, we

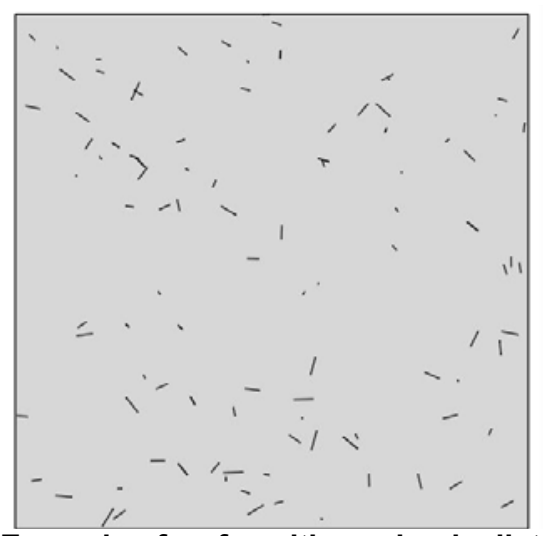

Fig. 2. Example of wafer with randomly distributed surface cracks used in Monte Carlo simulation. For legibility, the cracks are magnified 20 times. 


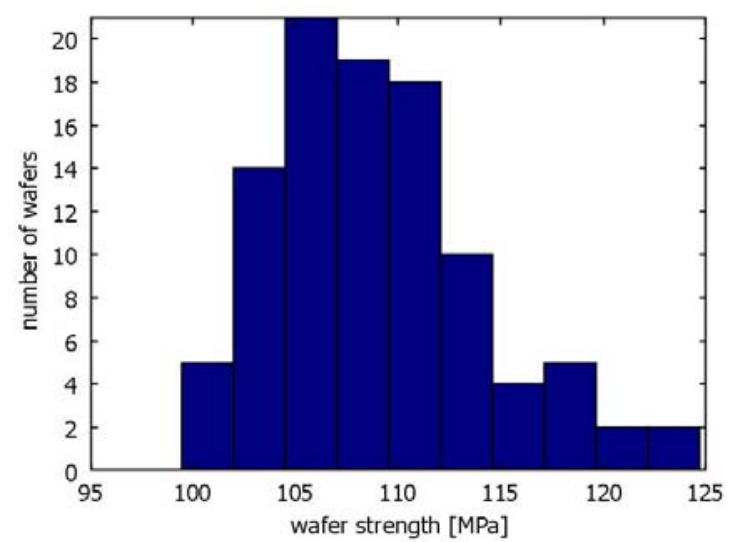

Fig. 3. Predicted wafer strength distribution for a statistical sample of 100 wafers

determine if the Weibull distribution can accurately fit the obtained results, and we find the corresponding Weibull parameters.

The computations performed in this study were based on the following assumptions: a) The surface energy of silicon, $\gamma_{0}$, is equal to $2.475 \mathrm{~J} / \mathrm{m}^{2}$, and density of subsurface microcracks is $0.32 / \mathrm{cm}^{2}$; b) The cracks are semi-elliptical in shape, and the crack plane is perpendicular to the wafer surface; c) The size of the cracks varies randomly within the specified ranges-the length, $L$, from 0 to $20 \mu \mathrm{m}$, and the depth, $D$, from 0 to $200 \mu \mathrm{m}$; d) We also assume that the entire wafer fractures once a single crack starts to propagate; e) The entire system is linearly elastic; and f) The cracks do not interact with the wafer edge or with each other. This last assumption implies that the strength of a wafer is controlled by one critical subsurface crack for which the rate of energy release is the highest.

As the interaction between cracks is neglected in our model, the stability of each crack can be analyzed separately. To predict the ultimate load for a wafer with one crack, we apply the fracture-mechanical computations based on gamma integrals [9] and the finite-element method.

\section{RESULTS AND DISCUSSION}

Fig. 3 depicts the predicted strength distribution for a statistical sample of 100 wafers (each containing 100 cracks). It can be observed that in our virtual experiment, the strength of wafers varied from 100 to $125 \mathrm{MPa}$, whereas the most probable value was $106 \mathrm{MPa}$. The graph in Fig. 3 follows the Weibull distribution very well. The fitting procedure yielded the following values for the three Weibull parameters:

$\alpha_{A}=0.205 \mathrm{MPa} m^{2 / \omega_{A}}, \omega_{A}=2.49$, and $\gamma_{A}=109 \mathrm{MPa}$.

The obtained strength distribution can be compared with the available experimental results from the literature.
References $[4,5]$ present experimental data for statistical samples of $\mathrm{PV}$ wafers tested in the as-sawn state, as well as after the 5-, 10-, and 20- $\mu \mathrm{m}$ etch ablation per side. By comparing (see Fig. 4), one can find that the strength distribution predicted in this study fits between experimental distributions for the as-sawn and $5-\mu \mathrm{m}$ etched wafers.

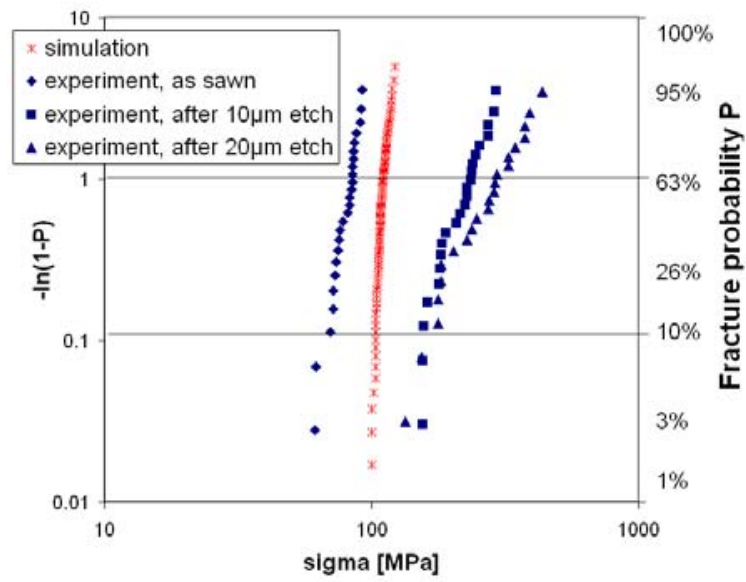

Fig. 4. Experimentally [4,5] and numerically obtained strength distributions for cast PV silicon wafers

\section{CONCLUSIONS}

A new expression, based on the multi-modal Weibull distribution, that takes into account the surface, edge, and bulk properties of a wafer has been proposed in this paper to describe the strength of the silicon wafers. We have presented a general fracture-mechanics model that can successfully predict the strength of the cast silicon wafers used by the PV industry. It has been shown that even with very limited surface damage data, the predicted wafer strength distribution agrees well with the available experimental results.

\section{ACKNOWLEDGMENTS}

This work was supported by the U.S. Department of Energy under Contract No. DE-AC36-99G010337 with the National Renewable Energy Laboratory.

\section{REFERENCES}

[1] Behnken, H., et al. Simulation of mechanical stress during bending tests for crystalline wafers. in $3^{\text {rd }}$ World Conference on Photovoltaic Energy Conversion. 2003. [2] Wormsen, A., et al. A statistical investigation of fatigue behaviour according to Weibull's weakest-link theory. in $15^{\text {th }}$ European Conference on Fracture, Stockholm, Sweden. 2004.

[3] Zinck, P., et al., Extrapolation techniques at short gauge lengths based on the weakest link concept for fibres exhibiting multiple failure modes. Philosophical Magazine a-Physics of Condensed Matter Structure Defects and Mechanical Properties, 1999. 79(9): p. 210322. 
[4] Wolstenholme, L.C., A Nonparametric Test of the Weakest-Link Principle. Technometrics, 1995. 37(2): p. 169-75.

[5] Möller, H.J., Basic Mechanisms and Models of MultiWire Sawing. Advanced Engineering Materials, 2004. 6(7): p. 501.

[6] Möller, H.J., et al., Multicrystalline silicon for solar cells. Thin Solid Films, 2005. 487(1-2): p. 179-87.

[7] Park, Y.K., et al. Correlation between wafer fracture and saw damage introduced during cast silicon cutting. in $15^{\text {th }}$ Workshop on Crystalline Silicon Solar Cells and Modules: Materials and Processes. 2005. Vail, Colorado. [8] Tobıas, I., et al., Handbook of Photovoltaic Science and Engineering, A. Luque and S. Hegedus, Editors. 2003, John Wiley \& Sons. p. 272.

[9] Cherepanov, G.P., Mechanics of brittle fracture. 1979, New York: McGraw-Hill International Book Co. xiv, 939 p. 


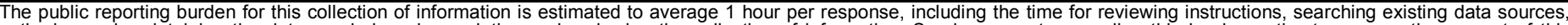

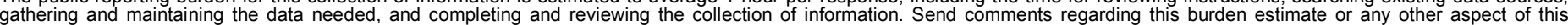

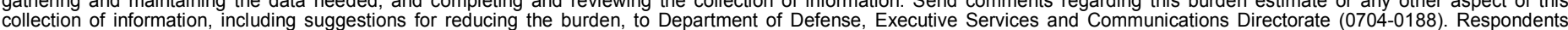

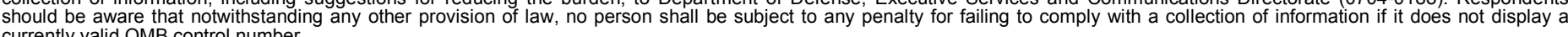

PLEASE DO NOT RETURN YOUR FORM TO THE ABOVE ORGANIZATION.

\section{REPORT DATE (DD-MM-YYYY) May 2008 \\ 2. REPORT TYPE Conference Paper}

4. TITLE AND SUBTITLE

Strength of Si Wafers with Microcracks: A Theoretical Model; Preprint
3. DATES COVERED (From - To)

11-16 May 2008

5a. CONTRACT NUMBER

DE-AC36-99-G010337

5b. GRANT NUMBER

5c. PROGRAM ELEMENT NUMBER

5d. PROJECT NUMBER

NREL/CP-520-42556

5e. TASK NUMBER

PVA73101

5f. WORK UNIT NUMBER

7. PERFORMING ORGANIZATION NAME(S) AND ADDRESS(ES)

National Renewable Energy Laboratory

1617 Cole Blvd. REPORT NUMBER

Golden, CO 80401-3393

NREL/CP-520-42556

9. SPONSORING/MONITORING AGENCY NAME(S) AND ADDRESS(ES)

10. SPONSOR/MONITOR'S ACRONYM(S) NREL

11. SPONSORING/MONITORING AGENCY REPORT NUMBER

12. DISTRIBUTION AVAILABILITY STATEMENT

National Technical Information Service

U.S. Department of Commerce

5285 Port Royal Road

Springfield, VA 22161

\section{SUPPLEMENTARY NOTES}

\section{ABSTRACT (Maximum 200 Words)}

Wafer breakage is a major problem in the photovoltaic industry and becomes more serious as the industry attempts to use thinner wafers. It is well established that the poor strength of PV wafers is primarily due to the presence of residual microcracks, which are generated by cutting and wafering procedures and are not removed by subsequent etching of the wafers. This paper addresses fracture mechanics modeling of the strength of silicon PV wafers. We are showing that the surface damage, which includes the subsurface microcracks, determines the ultimate strength of the PV wafers. The modeling of PV wafers consists of Monte Carlo simulations and finite-element analysis that is supported by the fracture energy theory for curved cracks. As an example, a virtual experiment on a statistical set of 100 wafers subjected to uniaxial tension is performed. The predicted strength distribution is shown to match well with the experimental results available in the literature.

\section{SUBJECT TERMS}

PV; silicon wafers; wafer breakage; residual microcracks; fracture energy theory; large-area; multimodal Weibull distribution;

\begin{tabular}{|c|c|c|c|c|}
\hline 16. SECURIT & CLASSIFICATI & N OF: & 17. LIMITATION & 18. NUMBER \\
\hline $\begin{array}{l}\text { a. REPORT } \\
\text { Unclassified }\end{array}$ & $\begin{array}{l}\text { b. ABSTRACT } \\
\text { Unclassified }\end{array}$ & $\begin{array}{l}\text { c. THIS PAGE } \\
\text { Unclassified }\end{array}$ & $\begin{array}{c}\text { OF ABSTRACT } \\
\text { UL }\end{array}$ & \\
\hline
\end{tabular}

19a. NAME OF RESPONSIBLE PERSON
19b. TELEPHONE NUMBER (Include area code)

